\title{
Depredador depredado: cacerías y comercio de jaguar en dos cuencas andino amazónicas
}

James León Parra Monsalve - Candidato a Magíster en Historia, Departamento de Historia, Universidad Nacional de Colombia

\begin{abstract}
Resumen
La cacería indiscriminada de jaguares y otros felinos menores en la región de los ríos Caquetá y Putumayo, especialmente durante los años 1940s - 1970s, responde a un proceso mucho más amplio de colonización y mercantilismo, que afectó profundamente a nuestra Amazonia durante todo el siglo XX. De esta forma, los ríos y los pobladores, al lado de todo tipo de documentos y vestigios, permiten rastrear un fenómeno de afectación deliberada de la biodiversidad amazónica, gracias al comercio internacional de pieles que, en los años de mayor apogeo, sumó cientos de miles de felinos muertos cada año en las selvas amazónicas. Este fenómeno, así como los imaginarios sobre el más grande felino americano y las posteriores medidas contra la cacería comercial impuestas desde los años 1970s, permiten comprender mejor la evolución de la relación sociedad - naturaleza en la región Caquetá-Japurá y Putumayo-Içá durante el último siglo.
\end{abstract}

\begin{abstract}
The indiscriminate hunting of jaguars and other minor felines in the region of Caquetá and Putumayo rivers, especially during the 1940s - 1970s, reflects a much broader process of colonization and mercantilism, which profoundly affects our Amazon throughout the twentieth century. In this way, rivers and villagers, along with all kinds of documents and relics keep track of a phenomenon of deliberate involvement of Amazonian biodiversity, thanks to international trade in skins which, in the years of greatest height, joined hundreds of Thousands of dead cats each year in the Amazon jungles. This phenomenon, as well as the imaginary about largest feline on the American and subsequent measures imposed against the commercial hunt since the 1970s, allows a better understanding of the evolving relationship society - nature in the region Caqueta-Japurá and PutumayoIçá during the last century.
\end{abstract}

\section{Palavras-chave}

\section{Keywords}

Jaguar, Caquetá, Japurá, Putumayo, Içá, Siglo XX.

Jaguar, Caquetá, Japurá, Putumayo, Içá, 20th Century. 


\section{INTRODUCCIÓN}

El presente artículo es síntesis de un trabajo de investigación comenzado hacia finales del año 2006, como propuesta para optar al título de Magíster en Historia de la Universidad Nacional de Colombia. Imaginarios, cacerías y comercio de jaguar en Caquetá-Japurá y Putumayo-Içá durante el siglo XX, fue el título del proyecto investigativo, que contribuye también en el esfuerzo iniciado años atrás por la Línea de Historia Ambiental y todos quienes han hecho posible este sueño de meterle un poco de ecología a la historia colombiana y latinoamericana.

Así entonces, la vida de las sociedades en el tiempo y su relación con la fauna, representada en el jaguar (Panthera onca), fue la coartada para estudiar el siglo XX y dos de las cuencas más importantes para Colombia, que son compartidas, a su vez, con Ecuador, Perú y Brasil. Una inmensa región rica en agua, aire, tierra, flora, fauna y gentes; y con una historia particular en lo relacionado con toda esta biodiversidad y el uso dado por las sociedades a estos recursos naturales de la selva húmeda tropical.

Esta perspectiva de análisis de nuestro pasado va también ligada a las discusiones ambientales, que en las últimas décadas del siglo XX fueron generadas a raíz de la transformación radical de los ecosistemas, por obra y gracia del ser humano. ${ }^{1}$ De igual forma, recoge algunos de los postulados más importantes de la geografía histórica y de la ecología política, ${ }^{2}$ como disciplinas afines a la investigación histórico-ambiental ${ }^{3}$. Además, la metodología incluyente propuesta

\footnotetext{
${ }^{1}$ Una importante relación de las presiones ambientales más acentuadas durante el siglo XX en el mundo puede verse en MCNEILL, J. R. Something New Under The Sun: An Environmental History of the Twentieth-Century World. New York: Norton \& Company, 2000. 422 p.

2 "se puede observar que la historia ambiental y la ecología política son puntos de llegada de diversas tradiciones, y también que han sido enriquecidas por la mezcla y por nuevos desarrollos." En: LEAL, Claudia. La naturaleza en los estudios sociales. Pp. 123. En: PALACIO CASTAÑEDA, Germán y ULLOA, Astrid (eds.). Repensando la naturaleza. Encuentros y desencuentros disciplinarios en torno a lo ambiental. Bogotá: Universidad Nacional de Colombia, Instituto Colombiano de Antropología e Historia y Colciencias, 2002. 246 p.

${ }^{3}$ Algunas de las actividades realizadas en el transcurso de la investigación corresponden a un esfuerzo por consolidar la Línea de Historia Ambiental de la Universidad Nacional de Colombia (Grupo Historia, Ambiente y Política), con temas que impliquen estudios nacionales y latinoamericanos. El grupo de personas interesadas en estos temas ha ido creciendo así con el tiempo y este año nuestra línea está terminando satisfactoriamente el proyecto Historia Ambiental de Colombia y América Latina II, al cual está adscrita la presente investigación. Del citado proyecto existe un sitio con los resultados más relevantes de su desarrollo: http://www.historiambiental.unal.edu.co/

Cabe anotar que algunos avances de la investigación fueron expuestos en el pasado encuentro de la Sociedad Latinoamericana y Caribeña de Historia Ambiental, SOLCHA, en mayo de 2008, en la Universidad Federal de Minas Gerais, donde hubo un espacio oportuno para compartir esas experiencias y resultados preliminares.
} 
para la etapa de pesquisa, creó una ventana propicia para reconocer la voz de los que no han tenido voz en la historiografía nacional, respondiendo al ánimo de inclusión postulado en el análisis crítico. En consecuencia, estos nuevos temas sobre las poco estudiadas relaciones sociedad - naturaleza dentro del contexto amazónico, permiten un acercamiento de la universidad pública con las regiones naturales, que es de tan beneficioso provecho para el conocimiento científico y social.

Esta investigación reconsideró igualmente el mito de las áreas protegidas como zonas "vírgenes" y, por extensión, sin una historia específica sobre las presiones sociales por el acceso a los recursos naturales. De forma que se buscó también elaborar una arqueología del jaguar como símbolo desde tiempos prehistóricos y su presencia contemporánea en el imaginario regional amazonense. La relación del hombre con el jaguar en América define la importancia histórica de esta especie para las sociedades asentadas a lo largo y ancho del continente.

De tal suerte, la averiguación propuesta analizó las dinámicas histórico ambientales de la cacería y comercialización de pieles y partes de felinos, en las cuencas de los ríos Caquetá-Japurá y Putumayo-Içá (Ilustración 1), como un espacio regional específico, y clarificó también las mentalidades de las sociedades indígenas y no indígenas sobre el jaguar (Panthera onca), durante el siglo pasado.

Además, con las fotografías, los vídeos y las entrevistas recopiladas durante el trabajo de campo, se pretende alimentar un acervo multimedia de la línea de investigación, que sirva de fuente para la historia ambiental de Colombia y América Latina en la Universidad Nacional de Colombia. 


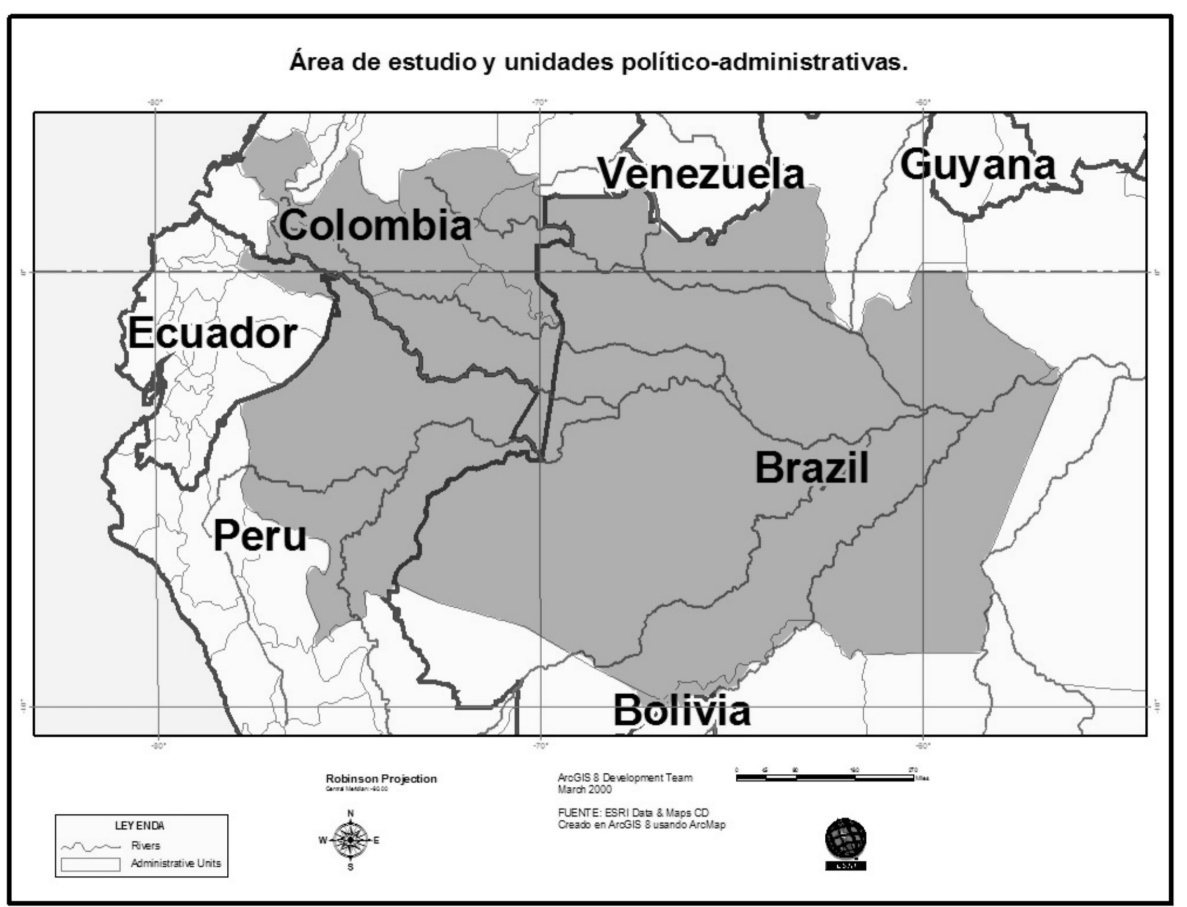

Ilustración 1: Unidades político-administrativas (sombreadas) relacionadas con las cuencas Caquetá-Japurá y Putumayo-Içá.

Fuente: elaborado por el autor a partir de mapa base en ARC GIS.

\section{TIERRA DE TRIBUS Y JAGUARES, RÍOS DE MONTAÑA Y SELVA}

Pero quizá el mapa de territorialidades político administrativas puede pasar por alto aspectos muy importantes en relación con la geografía regional amazonense. Desde sus nacimientos en los Andes, hasta sus desembocaduras en el río Amazonas (llamado Solimões por los brasileros hasta antes de su encuentro con el río Negro, en Manaus), estas cuencas representan una rica diversidad de ecosistemas, paisajes y culturas. Situación que conduce al historiador ambiental a verificar el contexto biofísico de su investigación (Ilustración 2). De tal suerte, la naturaleza ilumina a la cultura, al convertirse en fuente misma para la investigación historiográfica ambiental. Como un punto de partida necesario para reconocer físicamente el espacio y la diversidad de vida allí existente. 


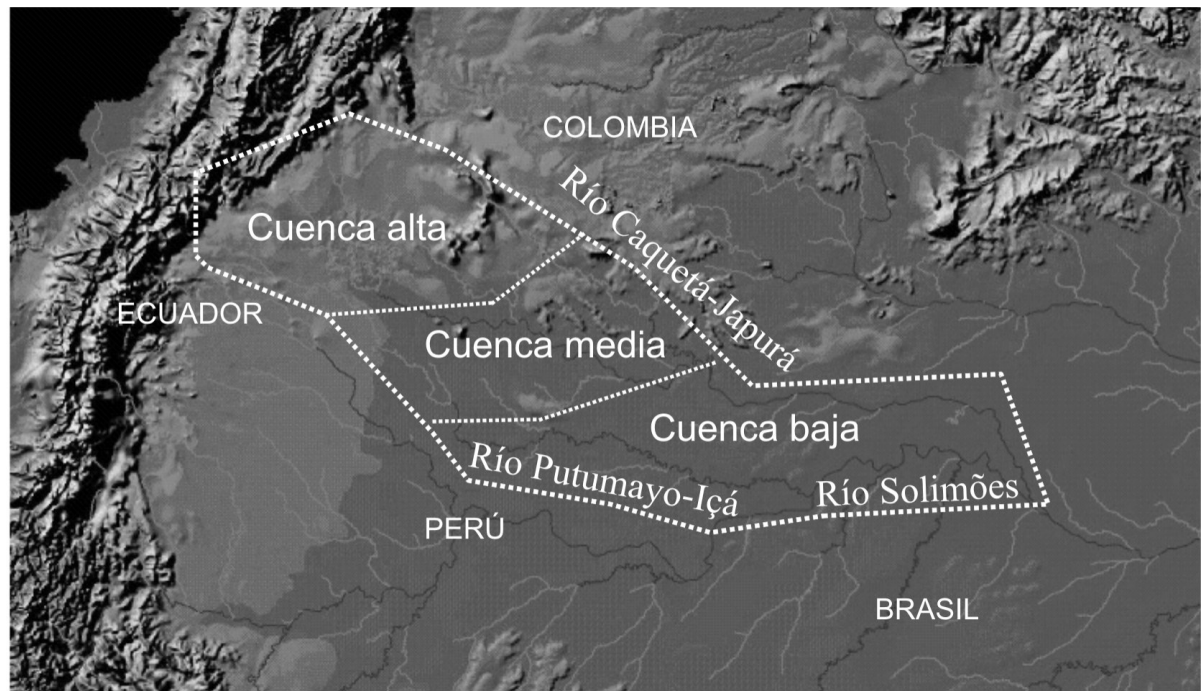

Ilustración 2: Zonificación del área estudiada.

Fuente: elaboración del autor con base en el mapa físico de la U. S. Geological Survey.

Estas cuencas representan así los paisajes característicos de la región noramazónica. La cobertura boscosa remanente en toda esta área, al finalizar el siglo XX, es caracterizada en la cuenca alta por bosques montanos, submontanos (en los Andes), sabanas, bosques bajos, bosques basales húmedos y bosques inundables (denominados también "várzeas"); mientras que la cuenca media posee algunas floraciones rocosas con matorrales, sabanas y bosques de serranía, además de bosques basales húmedos e inundables; por su parte, la cuenca baja está conformada por bosques basales húmedos y bosques inundables. ${ }^{5} \mathrm{La}$ precipitación de lluvias en la región está principalmente en el nivel de los $2.500 \mathrm{~mm}$., pudiendo llegar hasta un poco más de los $4.000 \mathrm{~mm}$., lo cual define su potencial en agua y humedad, mientras el clima promedio es de 26 grados centígrados debido a su ubicación ecuatorial. ${ }^{6}$

\footnotetext{
4 "La várzea es un ambiente extremadamente dinámico, sujeto a inundaciones anuales y a cambios en la morfología de sus terrenos, lo que torna difícil la ocupación humana." MAGALHÃES LIMA, Deborah de y FERREIRA ALENCAR, Edna. Histórico da ocupação humana y mobilidade geográfica de assentamentos na várzea do médio Solimões. P. 133. En: TORRES, Haroldo y COSTA, Heloisa (Orgs.). População e meio ambiente : debates e desafios. São Paulo: SENAC, 2000.

${ }^{5}$ MÁRQUEZ, Germán. Mapas de un fracaso. Naturaleza y conflicto en Colombia. Bogotá: Universidad Nacional de Colombia, 2004. P. 69 y ss. Cabe anotar que la cuenca alta es la más afectada por la transformación de los ecosistemas en el siglo XX, especialmente la zona piedemontana.

${ }^{6}$ CARRIZOSA UMAÑA, Julio. Cambios en la amazonia Colombiana en los últimos 300 años. En: Revista de la Academia Colombiana de Ciencias Exactas, Físicas y Naturales. Vol. 27, No 64, febrero de 1989. P. 120.
} 
Toda esta área ha sido hábitat natural del jaguar y de pueblos como los Yaiguaje, Inga, Huitoto, Siona, Kofán, Quichua, Secoya, Bora, Cocama, Yagua, Ocaina, Nonuya, Andoke, Tikuna, Yukuna, Carijona, entre muchas etnias más ${ }^{7}$ que reivindican al jaguar como animal simbólico. Mientras tanto, las sociedades no indígenas allegadas históricamente a la región han llevado la idea del jaguar como siendo una plaga para exterminar o como un recurso natural a explotar.

Entender tales condiciones biofísicas y socio culturales de la región CaquetáJapurá y Putumayo Içá, fue esencial para el análisis histórico ambiental del espacio escogido para dilucidar la época de las llamadas "tigrilladas". Valga decir que estos dos ríos ${ }^{9}$ y sus riberas han sido vías de comunicación histórica regional y de asentamiento poblacional, que explican algunas de las dinámicas socioeconómicas de la cacería y comercialización de pieles de jaguar. El caso de Manaus, Iquitos, Leticia y, más tarde, Florencia, vienen a confirmar la importancia de estas vías para el intercambio masivo de pieles, acaecido durante el siglo XX, y que tuvo en estas ciudades los principales polos de demanda de productos de fauna traída desde tales ríos.

Este trabajo de investigación abarcó una extensa revisión bibliográfica, principalmente en las ciudades de Bogotá, Leticia, Río de Janeiro e Iquitos. Además implicó un extenso trabajo de campo en diversas localidades ribereñas de las cuencas hidrográficas, a lo largo de su zonificación alta, media y baja.

La naturaleza y los modos sociales de producción y percepción ${ }^{10}$ fueron los nodos principales de la estructura temática presentada. De manera que esta tríada aportó un horizonte a seguir y una organización de los tópicos a escudriñar. En definitiva, se proyectó poner un tema ecológico en sus contextos sociocultural

\footnotetext{
${ }^{7}$ Para una relación más detallada de las etnias asentadas en la región véase: ARANGO OCHOA, Raúl y SÁNCHEZ GUTIÉRREZ, Enrique. Los pueblos indígenas de Colombia en el umbral del nuevo milenio. Bogotá: Departamento Nacional de Planeación, 2004. Pp. 53 y ss.

${ }^{8}$ Se estima que el ocelote fue el felino más perseguido desde comienzos de los $1960 \mathrm{~s}$ hasta mediados de los 1970s. Conocido popularmente también como "tigrillo" fue entonces este felino el que diera el nombre de "tigrilladas" a la cacería de felinos. Otros datos en: PAYÁN, Esteban y TRUJILLO Luis A. The Tigrilladas in Colombia. En: CAT NEWS. No 44, 2006. P. 25-28.

${ }_{9}$ De Paula y Monte-Mór definen así la importância de los rios para las diversas disciplinas: "Assim o rio, totalidade simples captada pelos biólogos, foi amplificada, desdobrando no rio captado pelo historiador, pelo economista, pelo engenheiro, pelo sociólogo, pelo cientista político, etc., isto é, o rio como totalidade complexa, "síntese de muitas determinações", para falar como Hegel e Marx." Tomado de: PAULA, João Antônio de y MONTE-MÓR, Roberto L. M. Biodiversidade, população e economia : uma experiencia interdisciplinar. Pp. 85-87. En: TORRES, Haroldo y COSTA, Heloisa (Orgs.). População e meio ambiente : debates e desafios. São Paulo: SENAC, 2000. P. 87. Véase también: LEONARDI, Victor Paes de Barros. Os historiadores e os rios : Natureza e ruína na Amazônia Brasileira. Brasília: Paralelo 15, Universidade de Brasilia, 1999. 272 p.

${ }_{10}$ WORSTER, Donald. Transformaciones de la tierra. Una antología minima de Donald Worster. Trad. Guillermo Castro Herrera. Panamá: s. e., 2000. 108 p.
} 
y temporal, ${ }^{11}$ atendiendo a su vez a la historia oral, dado que la temporalidad analizada (siglo XX) lo permite.

Explicar críticamente nuestro pasado ecológico fue del mismo modo una opción metodológica para el análisis del corpus discursivo colectado. Al respecto, durante el curso internacional "Análisis del Discurso en las Ciencias Sociales, la Cultura y el Territorio", realizado en Bogotá durante 2002, Robert Beaugrande ${ }^{12}$ presentó su propuesta de líneas de investigación enfocadas hacia temas ambientales y con el objeto de aportar en la construcción de sociedades ecológicamente más justas y eficaces. Sociedades que deberán entonces acoger los relatos del otro en su relación con la fauna, para, a fin de cuentas, conocerse mejor así mismas. Y esto efectivamente corresponde a las tareas del conocimiento académico científico.

En este orden de ideas, fue estudiada consecuentemente la ecología de la especie, ${ }^{13}$ para luego indagar por las cacerías, el comercio y los imaginarios, como puntos clave para preparar las entrevistas del trabajo de campo, y para la exégesis de las diversas fuentes documentales.

La citada investigación de campo tomó casi 10 meses de viajes y visitas a la región de las cuencas estudiadas. Durante este tiempo se pudieron efectuar 25 entrevistas (de las cuales 13 pudieron registrarse en formato digital) a moradores de la región, además de algunas charlas informales sobre el tema en sus casas y malocas. Más de 4.000 kilómetros de navegación fluvial en las cuencas dan cuenta de la diversidad de paisajes y gentes encontrados como manifestación misma de la naturaleza y la historia. Esto permitió testear las diversas hipótesis de investigación y recuperar de paso una parte de la historia oral amazonense. ${ }^{14}$ Igualmente se

\footnotetext{
${ }_{11}$ Tal como lo afirma MOSLEY: "But just as the best social history seeks to reconstruct the lives of ordinary people in the light of their own experiences, good environmental history attempts to place ecological concerns in their socio-cultural and temporal contexts, illuminating rather than distorting the past." Véase: MOSLEY, Stephen. Common Ground: Integrating Social and Environmental History. En: Journal of Social History. P. 919.

${ }^{12}$ UNIVERSIDAD NACIONAL DE COLOMBIA - INSTITUTO CARO Y CUERVO. Curso Internacional: Análisis del Discurso en las Ciencias Sociales, la Cultura y el Territorio. Bogotá, 2002. $232 \mathrm{pp}$.

${ }^{13} \mathrm{Al}$ respecto se revisaron principalmente: SEYMOUR, Kevin L. Panthera onca. En: Mammalian Species. No 340, octubre de 1989. p. 1-9. Además: BAPTISTE BALLERA, Luis Guillermo et al. Tras las huellas del jaguar. Inédito. Bogotá: Corporación Grupo Ecológico GEA, 1993. 180 p. También: ZULOAGA VILLAMIZAR, Juan Gerardo. Densidad de población, hábitos alimenticios y anotaciones sobre hábitat natural del jaguar (Panthera onca L.) en la depresión inundable del Bajo San Jorge, Colombia. Trabajo de grado. Bogotá: Departamento de Biología, Universidad Nacional de Colombia, 1995. 120 p. Sobre felinos en Perú consúltese: WUST, Walter H. Los gatos salvajes del Perú. En: Peru : El Dorado. No 15 (Abr-jun de 1997), pp 4-12.

${ }^{14}$ De forma que se tomaron la especialización regional y el trabajo de campo, al tenor de lo recomendado para la geografía histórica como objetivos disciplinares. Al respecto véase: SAUER, Carl O. Hacia una geografía histórica : Discurso a la Asociación Norteamericana de Geógrafos. Trad. Guillermo Castro H. Louisiana, 1940.
} 
obtuvo importante material fotográfico que alimentará el acervo de la Línea de Historia Ambiental de la Universidad Nacional de Colombia.

Por su parte, para la difusión del estado y los resultados de investigación se previó la creación de un blog personal (hambiental.blogspot.com), la producción de material para el sitio institucional de la línea (www.historiambiental.unal.edu. co), así como la presentación internacional de una ponencia y la preparación de un artículo para publicación en revista indexada. Finalmente y según el plan temático propuesto al iniciar el proyecto, fue dedicada otra parte de tiempo para la sistematización de archivos y la redacción y presentación de resultados.

\section{DEPREDADOR DEPREDADO}

El cambio acaecido en las cuencas de Caquetá-Japurá y de Putumayo-Içá durante el siglo XX, permite suponer una transformación paulatina del imaginario social hacia la utilización de una nueva tecnología, ${ }^{15}$ la cual permitiría más tarde, con las escopetas traídas por los caucheros ya desde el siglo XIX, la cacería masiva de jaguares y otros felinos menores, convertidos entonces en mercancías para los mercados extranjeros.

En 1913 Julio César Arana respondía así ante el parlamento británico por la difusión de las armas de fuego entre los indígenas de la región:

- [...] ¿Daban ustedes rifles Winchester a los indios salvajes?

- Algunos los tenían, pero no todos.

- ¿Los ha dado usted?

- Los empleados los dan, yo no.

- ¿A los indios salvajes?

- También a los salvajes. Cuando un indio se acerca a un blanco con caucho, se le da todo lo que se puede: se les dan hachas, rifles, escopetas, winchesters. ${ }^{16}$

\footnotetext{
${ }^{15}$ Santiago Mora señala que la introducción de nuevas herramientas entre las comunidades (como machetes y armas de fuego) han contribuido al deterioro ambiental y cultural pues "el reemplazo de las viejas tecnologías de caza, que implicaban la preparación de venenos por parte de especialistas, también ha conducido a la pérdida de los conocimientos necesarios para su producción." Véase el texto: Amazonía : pasado y presente de un territorio remoto : el ámbito, la bistoria y la cultura vista por antropólogos y arqueólogos. Bogotá: Universidad de los Andes y CESO, 2006. P. 184. ${ }_{16}$ ARANA, Julio César. Arana explica la Casa Arana: Extractos de la declaración ante el parlamento británico. En: Credencial Historia, No 160, 2003.
} 
Así las cosas, rifles Winchester, ${ }^{17}$ Mauser, ${ }^{18}$ Stevens ${ }^{19}$ y otros fueron intercambiados ampliamente en las cuencas durante el auge cauchero, siendo así un antecedente importante para entender cómo se había venido resolviendo una situación, que favorecería el comercio peletero internacional hacia mediados del siglo XX. Las rutas fluviales y localidades creadas a sangre y fuego con ocasión del boom gomífero ${ }^{20}$, legaron también a las cacerías sus trayectorias y nodos principales para la comercialización y acopio de pieles de jaguar.

Pero es hacia 1920 cuando la extracción de látex se reduce tres cuartas partes y, por el contrario, el comercio de productos de animales crece más de tres veces en la misma década en la Amazonia brasilera. ${ }^{21} \mathrm{El}$ subsector de productos animales se equiparó prácticamente al de extracción de plantas en esta economía para entonces (véase tabla 1), con lo cual la presión sobre los animales silvestres, en una escala sin precedentes, comenzaría a afectar a la Amazonia. Esto puede llevar a pensar de igual modo que para las regiones brasilera y peruana esta sustitución de herramientas tradicionales por armas de fuego fue más temprana en el siglo XX, que para la colombiana. La tercera década confirmaría esta tendencia a raíz del

\footnotetext{
${ }^{17}$ La Winchester Repeating Arms Company, fue creada en 1866 en New Haven, Connecticut, año en que absorbió a la New Haven Arms Company, creada desde 1857. Al respecto consúltese: Asociación de Coleccionistas de Armas Winchester: <http://www.winchestercollector.org/ > Fue una de las compañías que proveyó rifles para la conquista del oeste americano y también para las casas caucheras en el Amazonas a finales del siglo XIX y comienzos del XX.

${ }^{18}$ La compañía alemana Mauser, fabricante de fusiles desde 1834, había sido fundada desde este año por Wilhelm y Paul Mauser, quienes desde pequeños habían trabajado en la fábrica real de armas en Oberndorf/Neckar, Alemania. Para 1871 la Mauser Brothers \& Co. Weapons Factory, en Oberndorf, había conseguido pasar de los 800 a los 1800 metros en alcance de penetración de sus balas. Un recuento de la empresa entre 1834 y 2003 en: <http://www.mauserwaffen.de/ History.155.0.html? \&L=1>, accesado el 13 de octubre de 2008.

19 La J. Stevens \& Co fue una de las más importantes compañías militares estadounidenses fabricantes de armas y munición desde su fundación en 1864. Aunque fue comprada en 1920 por Savage Arms, la Steven Company difundió en el mundo armas con ocasión de la Primera Guerra Mundial y para la consolidación del control de mano de obra por parte de caucheros como se puede observar en la región estudiada. Para más información acceda a $A$ CENTURY OF Quality Firearms Development [en línea]. Savage Arms, 2005. Accesado el 10 de Julio de $2008<$ http:// www.savagearms.com/history.htm>.

${ }^{20} \mathrm{Al}$ respecto pueden verse: PINEDA CAMACHO, Roberto. Holocausto en el Amazonas : historia social de la Casa Arana. Bogotá: Planeta, 2000. 255 p., también DOMÍNGUEZ, Camilo y GÓMEZ, Augusto. Nación y etnias : Conflictos territoriales en la Amazonia colombiana 1750-1933. Santafé de Bogotá: COAMA, Unión Europea, 1994. 246 p. y GÓMEZ, Augusto et al. Caucherías y conflicto colombo-peruano : testimonios 1904-1934. Santafé de Bogotá: Disloque Editores, 1995. $318 \mathrm{p}$.

${ }^{21}$ En 1920 y por primera vez desde 1890, la extracción de plantas, renglón primario de la economía, caía ostensiblemente a 57.182 contos de réis, después de haber llegado en 1910 a 197.811 . BARHAM, Bradford L. y COOMES, Oliver T. Reinterpreting the Amazon Rubber Boom: Investment, the State, and Dutch Disease. En: Latin American Research Review, Vol. 29, No 2, 1994, P. 89. pp. 73-109
} 
conflicto colombo peruano, luego del cual se delimitaron las fronteras amazónicas ecuatorianas, peruanas, brasileras y colombianas, incidiendo negativamente en su poblamiento hasta $1946^{22}$ y difundiendo una cantidad importante de rifles en la región.

Tabla 1: Sector Económico Primario en el Amazonas brasilero, 1890-1920, en contos de réis.

\begin{tabular}{|l|r|r|r|r|}
\hline \multicolumn{1}{|c|}{ Sector económico } & \multicolumn{1}{c|}{$\mathbf{1 8 9 0}$} & \multicolumn{1}{c|}{$\mathbf{1 9 0 0}$} & \multicolumn{1}{c|}{$\mathbf{1 9 1 0}$} & \multicolumn{1}{c|}{$\mathbf{1 9 2 0}$} \\
\hline PRIMARIO & 53.953 & 181.040 & 218.287 & 123.507 \\
\hline Agricultura & 8.143 & 20.833 & 9.593 & 31.251 \\
\hline Extracción de plantas & 37.914 & 141.484 & 197.811 & 57.182 \\
\hline Productos animales & 7.896 & 18.723 & 10.883 & 35.074 \\
\hline
\end{tabular}

Fuente: Barham y Coomes, 1994, p. 89

No obstante, una difusión regional más generalizada -que incluyó también varios sectores colombianos en las cuencas- viene a concretarse hacia mediados de los años 1940s, cuando ha pasado el tiempo catártico de la delimitación fronteriza y los conflictos caucheros. Una nueva generación de huérfanos indígenas y mestizos, y de colonos que buscaban cómo ganarse la vida en áreas plenas de recursos naturales, se apresuró a tomar oficios relacionados con la extracción y comercialización de pieles de animales silvestres. Desde Iquitos, por ejemplo, fueron exportadas 762.846 pieles entre 1935 y 1949 (Tabla 2), que ya indican la magnitud y el incremento de este comercio que sobrepasó el medio millón de ejemplares sólo en los años 1940s en la Amazonia peruana.

Tabla 2: Número de pieles exportadas desde Iquitos a Europa, 1935-1949

\begin{tabular}{|l|r|}
\hline \multicolumn{1}{|c|}{ Año } & \multicolumn{2}{c|}{$\mathbf{N}^{\mathbf{0}}$ pieles exportadas } \\
\hline 1935 & 73.045 \\
\hline 1940 & 171.732 \\
\hline 1946 & 497.741 \\
\hline 1949 & 20.328 \\
\hline TOTAL & 762.846 \\
\hline
\end{tabular}

Fuente: Ríos Zañartu, 1999.

En décadas siguientes, entre 1946 y 1966, Iquitos exportó 150.806 pieles de felinos, de las cuales 12.704 eran de jaguar, exportadas hacia Europa, Japón y

\footnotetext{
${ }^{22}$ Como afirma Arcila Niño et al "Después el conflicto y hasta 1946 se vivió un poblamiento lento, no muy denso y con una ocupación esporádica. No obstante, esta fase dejaría rutas para el proceso de colonización y asentamientos que posteriormente se consolidaron." En: Caquetá : construcción de un territorio amazónico. Bogotá: Instituto Amazónico de Investigaciones Científicas, 2000. P. 40.
} 
Norteamérica. ${ }^{23}$ Aunque estas casi 13 mil pieles de otorongo ${ }^{24}$, que representan casi 9 por ciento del total, puedan significar más bien la paulatina reducción del número de Panthera onca en la región selvática peruviana, debido especialmente a la sobre explotación de la especie desde finales del XIX y el vuelco hacia las especies de felinos menores a partir de los años 1960s. ${ }^{25}$

Estas cifras hasta comienzos de los años 1970s siguen alcanzando altos niveles pues, si se sigue a Carrizosa Umaña ${ }^{26}$, hubo registros de 452.500 pieles exportadas entre 1969 y 1973, de las cuales 3.500 fueron de jaguar y 20.000 de tigrillos (Tabla 3). Aunque pueda entenderse también que la demanda del mercado se haya trasladado asimismo durante estos años hacia los grandes lagartos por sus más de 300.000 ejemplares sacrificados.

Tabla 3: Volumen de pieles exportadas desde la Amazonia para el período 19691973.

\begin{tabular}{|l|r|}
\hline \multicolumn{1}{|c|}{ Especie } & \multicolumn{1}{c|}{ Volumen de pieles } \\
\hline Babillas & 333.500 \\
\hline Saino, cafuche, huangana y manao & 83.300 \\
\hline Tigrillo (20.000) y jaguar (3.500) & 23.500 \\
\hline Venado & 4.800 \\
\hline Chigüiro & 3.900 \\
\hline Nutria & 3.500 \\
\hline TOTAL & 452.500 \\
\hline
\end{tabular}

Fuente: Elaboración propia a partir de Carrizosa Umaña, 1989.

Aunque sería necesario integrar datos sobre la exportación de pieles desde la cuenca en sus sectores brasileros, es cierto que sumadas las cifras peruanas y colombianas en sus regiones amazónicas, se cazó a un ritmo de dos jaguares por día durante 27 años. Para el Brasil este índice podría ser muy superior debido al crecimiento demográfico del puerto de Manaus y sus facilidades para enviar todas estas "mercaderías" por todo el mundo, gracias al río mar. Por otro lado no se consideran aquí, en su debida extensión, las facilidades con las cuales el contrabando

23 REDFORD, 1991, citando a GRIMWOOD, I. R. Notes on the distribution and status of some Peruvian mammals. Spec. Pub. 21. New York Zool. Soc., 1968.

${ }^{24}$ Palabra de origen quechua, con la cual nombran al jaguar en Perú.

25 "The trade in cat skins began with jaguars at the end of the last century. In the 1960s, apparently in response to overexploitation of jaguar and the concomitant decrease in numbers, the cat trade shifted to smaller species." Ibíd. Pp. 14-16. Aquí el autor propone estas ideas tomadas de MCMAHAN, L. R. The international cat trade. pp. 461-88. En: Cats of the World: Biology, conservation and management. Eds. S. D. MILLER y D. D. EVERETT. Washington, National Wildlife Federation.

${ }^{26}$ CARRIZOSA UMAÑA, Julio. Cambios en la amazonia Colombiana en los últimos 300 años. En: Revista de la Academia Colombiana de Ciencias Exactas, Físicas y Naturales. Vol. 27, No 64, febrero de 1989. pp. 119-123. 
operaba para la época en los territorios amazónicos peruanos y colombianos y por supuesto desde estos hacia Brasil y viceversa; en tal caso este ritmo de presión sobre el jaguar podría elevarse a varios individuos más por día durante las décadas de la bonanza peletera.

Sin embargo y tan importante como la cacería comercial masiva ha sido la cacería furtiva con objeto de eliminar jaguares "problema". Así también los felinos se convirtieron en enemigos potenciales de los hatos ganaderos, con su consecuente eliminación por ser obstáculos naturales para las actividades pecuarias. ${ }^{27}$ Una mayoría de las personas entrevistadas durante el trabajo de campo confirman el problema de los animales domésticos capturados y muertos por felinos en las haciendas y los resguardos de las cuencas. ${ }^{28}$

No obstante esto sucedió con mayor profundidad en las zonas piedemontanas y a lo largo de los canales principales de las altas cuencas CaquetáJapurá y Putumayo-Içá, versus muchos de las tierras aledañas a los afluentes de la cuenca media y baja, que aún conservan un alto número de individuos y de sus presas. ${ }^{29}$ Así entonces la gran hacienda ganadera en el Amazonas se convirtió en un obstáculo para el desarrollo adecuado ${ }^{30}$ de una región con vocación más agroforestal y de reservorio de biodiversidad.

Es (in)justamente la cuenca alta de la región la que ha venido perdiendo paulatinamente sus poblaciones de jaguares, aún después de la prohibición de su caza y debido fundamentalmente a la deforestación, la producción agropecuaria y petrolera, la construcción de infraestructura y, en menor medida, los cultivos

\footnotetext{
${ }^{27}$ Para el caso venezolano, por ejemplo, se han aplicado programas de conservación de la especie, apoyando a los mismos ganaderos en la gestión del problema de depredación en las haciendas: HOOGESTEIJN, Rafael. Manual sobre problemas de depredación causados por jaguares y pumas en hatos ganaderos. Apure: Wildlife Conservation Society, s.d. 39 p.

28 Así como lo relata también Juan de Dios Soto Parra, residente del bajo Guaviare: "En el año 1976, un tigre mató seis reces (sic); un toro de 20 de arrobas, una vaca y cuatro terneros." En: ROMERO RAFFO, Manuel. Canaguaro, la guerra de los tigreros. Bogotá: Parature Editores, 2005. P. 52.

${ }^{29}$ Según un reporte de recursos biológicos publicado en 2004 "En Yaguas [tributario del Putumayo] documentamos lo que podría ser la densidad más alta de tapires de tierras bajas (Tapirus terrestris) del mundo, con más de 11 observaciones directas en un período de dos semanas. En este mismo lugar encontramos un grupo de huanganas (Tayassu pecari) con un estimado de 500 animales. Durante el inventario también registramos un gran número de mamíferos de especies amenazadas y raros en la Amazonía, tales como el armadillo gigante (Priodontes maximus), perro de orejas cortas (Atelocynus microtis), oso hormiguero gigante (Myrmecophaga tridactyla) y otorongo (Panthera onca)." Véase: PITMAN, Nigel et al (eds). Perú : Ampiyacu, Apayacu, Yaguas, Medio Putumayo. Rapid Biological Inventories Report 12. Chicago: The Field Museum, 2004. 274 p.

30 SERRANO MOYA, Edgar David. El modelo ganadero de la gran hacienda: Un paso atrás en el desarrollo del Caquetá. Trabajo de Investigación. Florencia: Universidad de la Amazonía, 1994. $164 \mathrm{p}$.
} 
ilícitos para la extracción de cocaína. ${ }^{31} \mathrm{El}$ análisis de estas presiones humanas en relación con el hábitat del jaguar condujo entonces a explorar el tema de su fragmentación y pérdida, generados especialmente por estas presiones que fomentaron la colonización, la cual creció exponencialmente a partir de los años 1940s en la región y consolidó así su poblamiento (Véase Ilustración 3); lo cual condujo, en alguna medida, a la fijación de patrones de consumo e industrialización insostenibles para la conservación biológica, en un área de importancia ecológica para los diferentes países que delinean por allí sus fronteras. ${ }^{32}$

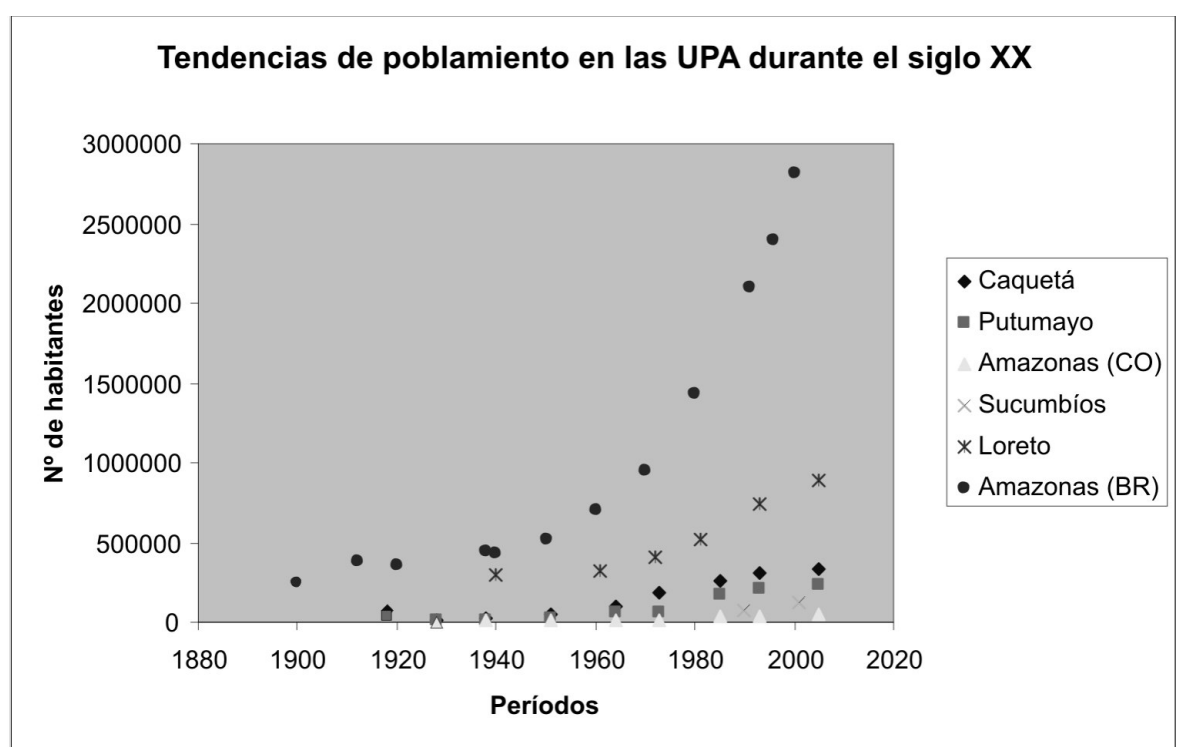

Ilustración 3: Tendencia de poblamiento en las unidades administrativas regionales durante el siglo $\mathrm{XX}$.

Fuente: elaboración del autor con base en datos de IBGE, INEI, INEC y DANE.

Se sugiere pues, que los orígenes de la generalización de la cacería masiva de jaguares en la región estudiada se pueden ubicar hacia la mitad de los años 1940s. La continua migración de gentes desde el interior de los países amazónicos hacia esta región parece también confirmarlo. La cantidad de fauna existente atrajo entonces a muchos interesados en pieles que se transformarían luego en sombreros,

\footnotetext{
${ }^{31}$ Una versión más amplia de este análisis puede consultarse La reducción de un hábitat o de cómo el jaguar va perdiendo su hogar, capítulo número 1 de Imaginarios, cacerías y comercio de jaguar en Caquetá-Japurá y Putumayo-Içá durante el siglo XX, tesis de maestría, Bogotá: Departamento de Historia, Universidad Nacional de Colombia, 2008.

${ }^{32}$ Respecto a las poblaciones de la cuenca amazónica en general puede verse también: ARAGÓN VACA, Luis E. (Editor). Populações da Pan-Amazônia. Belém: Núcleo de Altos Estudos Amazônicos, 2005. $204 \mathrm{p}$.
} 
bolsos, chaquetas y demás artículos comercializados principalmente en Europa, Norteamérica y Japón. Al finalizar el siglo XX, las anteriores presiones humanas sobre los ecosistemas de la parte alta de estas cuencas, consiguieron erradicar la especie de buena parte del piedemonte y la selva alta. ${ }^{33}$

El mapa histórico del jaguar y su hábitat a 2001 en América (Ilustración 4), permite observar esta situación crítica para la conservación de las poblaciones de jaguares colombianos, existentes hoy en día en la cuenca alta Putumayo-Caquetá. Lo que no es así para la cuenca media y baja, donde existen aún poblaciones que pueden asegurar una mayor duración de la especie en el futuro.

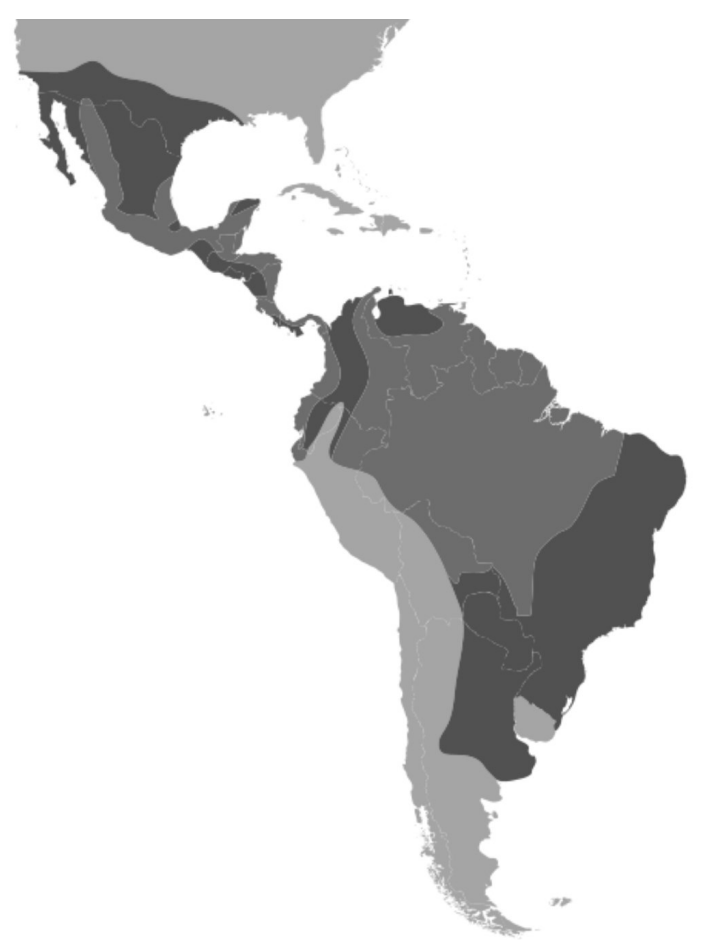

Ilustración 4. Hábitat histórico de jaguar (rojo) y hábitat a 2001 (verde). Fuente: Medellín et al. P. 523.

\footnotetext{
${ }^{33}$ Según el GEO4 "En la actualidad, el crecimiento de la población y los patrones de consumo, que conducen a un incremento de la demanda de servicios del ecosistema y energía, son los factores desencadenantes más importantes que afectan a la biodiversidad. Estos factores desencadenan presiones que generan impactos directos sobre los ecosistemas, las especies y los recursos genéticos. Las actividades humanas provocan cambios tanto en los componentes vivos como en los componentes inertes de los ecosistemas, y estas presiones se han incrementado drásticamente a lo largo de las décadas más recientes." Véase: PROGRAMA DE LAS NACIONES UNIDAS PARA EL MEDIO AMBIENTE. Perspectivas del Medio Ambiente Mundial. GEO4 : medio ambiente para el desarrollo. Dinamarca: PNUMA, 2007. P. 167.
} 
De otro lado, considerando al jaguar como especie focal que permite valorar el estado mismo de los ecosistemas, ${ }^{34}$ se empiezan a conocer aspectos interesantes en materia de conservación y conocimiento de la biodiversidad amazonense. Precisamente el área estudiada tiene una ubicación geoestratégica por la cantidad de energía solar que recibe al año y la calidad de sus ecosistemas para mantener tan diversos seres que habitan su biosfera. La historia ambiental de Putumayo así lo enseña, como evidencia también la pérdida de biodiversidad ${ }^{35}$ acaecida durante el siglo XX, en la cual no sólo se ha perjudicado el hábitat del jaguar sino también a una serie de ecosistemas.

Este crecimiento inusitado de la cacería de animales para la extracción de sus pieles es así el síntoma y la contribución material del hombre en la pérdida de biodiversidad en las cuencas Caquetá y Putumayo. Es historia, pero precisamente las decenas de miles de pieles de jaguares, exportadas durante los años 1940s-1970s, muestran una clara aceleración de los patrones de consumo y opulencia.

$\mathrm{Y}$ mientras por un lado se dictan normas tendientes al comando y control estatal de nuevas áreas de protección ambiental, y se sancionan leyes que se dicen incluyentes en el tema del manejo de los recursos naturales, ${ }^{36}$ por el otro los ecosistemas van perdiendo su diversidad biológica, a costa de la nación y especialmente de los pueblos asentados históricamente en estos territorios. ${ }^{37} \mathrm{Y}$ puede considerarse no sólo como un problema latinoamericano del pasado, dado que en los países que conservan poblaciones de jaguar existen evidencias, más o menos recientes, de mercadeo persistente. Marcelo Aranda, durante una estadía

\footnotetext{
${ }^{34}$ INSTITUTO DE INVESTIGACIÓN DE RECURSOS BIOLÓGICOS ALEXANDER VON HUMBOLDT (IAvH). Los felinos como especies focales y de alto valor cultural. (Especies Colombianas, $\left.n^{\circ} 7\right)$.

${ }^{35}$ Con este concepto se puede entender la diversidad (en variedad y variabilidad) de vida que hay en los genes, especies y ecosistemas existentes en el planeta tierra. Al respecto léase: RUEDA, Martha Emilia. La biodiversidad. Un asunto nacional con implicaciones globales. En: Pensamiento Jurídico. No 2, 1995, Bogotá. P. 66. La Amazonia colombiana conserva precisamente "importantes zonas cubiertas de bosque húmedo tropical y ricas en biodiversidad." En donde por los "intereses globales" ha existido un manejo amañado de los recursos naturales, que nos muestra la "diferencia entre el país político y el nacional." Cf. TRIANA ANTORVEZA, Adolfo. La Amazonia: economía y derecho internacional. En: Pensamiento Jurídico. № 6, 1996. Bogotá. Pp. 123-153.

${ }^{36}$ Un recorrido por la evolución de las instituciones ambientales colombianas desde la creación del Instituto Nacional de Recursos Naturales en 1968 hasta 2004, pasando por la Ley 30 de 1993 que creó el Ministerio del Ambiente y reorganizó el sector ambiental colombiano en los años post constitución de 1991. Véase: URIBE BOTERO, Eduardo. The Evolution of Colombian Environmental Institutions: 1971-2004. Bogotá: Universidad de los Andes, 2005. 92 p.

37 En este caso se difunde una teoría incluyente, pero la práctica dista mucho de serlo, creando una divergencia radical entre teoría y práctica. Véase más detalladamente en: BEAUGRANDE, Robert de. Curso Internacional: Análisis del Discurso en las Ciencias Sociales, la Cultura y el Territorio. Bogotá: UNIVERSIDAD NACIONAL DE COLOMBIA - INSTITUTO CARO Y CUERVO, 2002. $232 \mathrm{p}$.
} 
en San Cristóbal de las Casas, México, entre julio de 1985 y febrero de 1987, y, en Comitán, entre septiembre de 1986 y febrero de 1987, pudo visitar 32 tiendas en el primero y 16 en el segundo, documentando así el comercio de pieles de diversos animales, además de felinos, a pesar de la promulgación de la Ley Federal de Caza de 1952, que prohibió este tipo de comercio en México. ${ }^{38}$ Un país que ha afrontada una grave pérdida del hábitat del jaguar, pero que está buscando efectivamente la colaboración internacional en su estudio y protección. ${ }^{39}$

Pero también esta historia revela la transformación paulatina de los imaginarios y la realidad misma para permitir efectivamente la degradación de la tierra y la pérdida de las especies amazonenses, en un pasado no muy lejano. Esta dinámica puede verse reflejada en los conflictos por el acceso a los recursos o a la misma mano de obra, como muy bien lo demostraron desde finales del siglo XIX los caucheros de Iquitos y Manaus. ${ }^{40}$ Así entonces el jaguar pudo ser una de esas mercancías de frontera, comercializadas en los mercados internacionales en detrimento de aquellas especies y ecosistemas regionales. La demanda surtida desde tierras ultramarinas por las pieles de jaguar, contrastaba con las ideas sobre la civilización y el progreso que pregonaba la industria petrolera en los años 1960s, mientras desconocían de facto el derecho de las comunidades asentadas en esas tierras para vivir, disfrutar y proteger de los recursos naturales allí existentes.

Veamos entonces cuál era el sentido de esa "civilización” para entender un poco de lo que se habla aquí, a partir de una campaña de reclamos publicitarios difundidos en la Revista del Petróleo ${ }^{41}$, publicación que circuló durante los años 1950s y mediados de los 1960s en Colombia:

Este texto indica así que la utilización de campañas como "A LO PROFUNDO DE LA SELVA... LLEGA LA CIVILIZACIÓN”42, señala un

${ }^{38}$ Consúltese: ARANDA, Marcelo. Wild Mammal Skin Trade in Chiapas, Mexico. Pp. 174-177. En: REDFORD, Kent H. y ROBINSON, John G. Neotropical Wildlife Use and Conservation. Chicago: The University of Chicago Press, 1991. 520 p.

${ }^{39}$ MEDELLÍN, Rodrigo A. et al. El jaguar en el nuevo milenio. México: Fondo de Cultura Económica, 2002. 648 p.

${ }^{40}$ Por estas ciudades transitaron toneladas de caucho que representaron el fundamento de su crecimiento económico, no obstante en las tierras de frontera, desde donde generalmente se traía el caucho, se ejecutaban prácticas de genocidio y coacción por parte de empleados de los señores del caucho. Para ver el caso Airão, en el alto río Negro y su relación histórica con Manaus, cf. LEONARDI, Victor Paes de Barros. Os historiadores e os rios : Natureza e ruína na Amazônia Brasileira. Brasília: Paralelo 15, Universidade de Brasilia, 1999. 272 p.

${ }^{41}$ La Revista del Petróleo fue una publicación que se editó en Bogotá entre 1950 y 1966 y difundía y defendía los intereses de la industria del petróleo en Colombia. En la Biblioteca Luis Ángel Arango se encuentra una colección completa, organizada en 17 volúmenes y 178 números, que conforman la muestra total de los años de publicación.

${ }^{42}$ Publicidad aparecida recurrentemente durante los últimos 6 años de la Revista del Petróleo (1961-1966). 
remanente del pasado colonial en plena república que, a través del discurso de la “civilización”, legitimó el despojó de sus valores ancestrales y de sus riquezas a los aborígenes americanos y que, por inercia, es la estrategia de que se valen los publicistas de la revista para idealizar la labor de esta industria en los años 1960s. Pero es aquí cuando "El ecologismo aspira a reconstruir tales divisiones con el principio de darles poder a todos estos grupos que poseen diferentes clases de conocimientos y quitarle crédito a la desautorizante noción de que algunos grupos carecen de conocimiento y solo poseen ignorancia." ${ }^{43}$ Es así que el conocimiento nativo sobre los jaguares y otros felinos fue también relegado frente al discurso científico y social sobre la fauna silvestre, y esto ha fundamentado históricamente las políticas públicas en materia de conservación de biodiversidad en Colombia. En consecuencia, sigue siendo común la gestión ambiental excluyente de los conocimientos tradicionales en relación con la naturaleza, no obstante existe un marco normativo que supuestamente debe incentivar la inclusión y protección en materia de diversidad natural y cultural.

La metodología seguida a lo largo del trabajo de campo permitió igualmente resaltar el valor que tiene la oralidad para la construcción de una historia ambiental amazónica. De esta manera, se consiguió el objetivo de testear las hipótesis de trabajo de una forma que acogiera el mayor número de fuentes sobre el tema, las cuales aún siguen siendo pocas en los centros de documentación regionales, por lo cual es menester echar mano de las diferentes potencialidades que los testimonios aportan al trabajo investigativo.

En cuanto a la delimitación territorial de la investigación, ir más allá del estrecho marco político administrativo, implicó un análisis desde la perspectiva de cuenca hidrográfica, lo cual brindó la base propicia para el estudio de la relación sociedad jaguar en Putumayo-Içá y Caquetá-Japurá. Combinar entonces la investigación de los elementos biofísicos con la de los socio culturales, fue una apuesta por entender mejor al siglo XX y su historia en esta región suramericana. Las principales tendencias poblacionales registradas por las unidades administrativas desde finales del siglo XIX en Brasil y, entrado el siglo XX, en Colombia y Perú, enseñan el crecimiento exponencial de la colonización de vastos territorios considerados muchas veces como baldíos, tierras vírgenes o de nadie; sin una historia posible para sus moradores y los sitios sagrados, pero con las puertas abiertas para la entrega de recursos naturales a los mercados peleteros internacionales.

\footnotetext{
${ }^{43}$ Entendiendo ecologismo, claro está, como la "agenda que promueve la convergencia dialéctica entre las teorías y las prácticas inclusivas en el interior de la democracia.” Op Cit. BEAUGRANDE, Robert de. P. 42.
} 


\section{LA GENTE JAGUAR VERSUS EL JAGUAR PROBLEMA}

Desde tiempos precolombinos el jaguar ha sido un icono presente en manifestaciones culturales indígenas. ${ }^{44}$ Buena parte de América manifiesta la expresión jaguarina como un legado cultural que caracteriza a las tribus que se lograron adaptar al continente americano. ${ }^{45}$ Además del sitio arqueológico de San Agustín, tan rico en esculturas con rasgos felinos en piedra, ${ }^{46}$ las representaciones étnicas tienen en el jaguar también un símbolo importante dentro de su historia. ${ }^{47}$ En consecuencia, se puede establecer una memoria del jaguar en diversos ámbitos de las sociedades americanas, que lleva incluso a fundamentar sus orígenes como pueblos con unos rasgos culturales específicos. Es el animal simbólico que sirve para ordenar su mundo; para ordenar su sociedad.

El caso de las cerámicas Chavín, en Perú, datadas desde un milenio antes de nuestra era, y que representan materialmente la cercana relación del chamán con el jaguar en territorio incaico, es una muestra es una muestra objetiva. ${ }^{48}$ Esta relación presenta interesantes indicios que explican mejor la interacción sociedad naturaleza en las sociedades del Vaupés y el Apaporis, en el Bajo río Caquetá, donde los huesos del animal han sido utilizados también como recipientes para

\footnotetext{
${ }^{44}$ Véase al respecto: CABELLOS CARRO, Paz. Iconografía y significado del jaguar en pueblos mesoamericanos chorotecas y nicaraos. En: Revista Española de Antropología, Madrid, No 10, 180, pp. 43-66. También: DAVIS, Whitney. So-Called Jaguar-Human Copulation Scenes in Olmec Art. En: American Antiquity, Vol. 43, No 3 (Jul., 1978), pp. 453-457. Además: DAGGETT, Pierre M. y HENNING, Dale R. The Jaguar in North America. En: American Antiquity, Vol. 39, No 3 Jul., 1974), pp. 465-469. Y: COVARRUBIAS, Miguel. El águila, el jaguar y la serpiente: Arte indígena americano : América del Norte: Alaska, Canadá, los Estados Unidos. Trad. Sol Arguedas. México: Universidad Nacional Autónoma de México, 1961. 340 p.

${ }^{45}$ Sobre la relación hombre-jaguar en varias comunidades indígenas colombianas, para los años 1980s: "El estado actual de la información antropológica y arqueológica ya permite adentrarse en análisis de los simbolismos socio-ecológicos y mitológicos que permean no solamente la vida contemporánea de las comunidades indígenas. Sino también las obras artísticas que en el pasado fueron motivadas por el pensamiento filosófico de tal o cual sociedad indígena. Y en esa ruta de trabajo es que las figuras del jaguar y de la anaconda surgen con enorme persistencia impregnando variados ángulos de cada uno de los grupos indígenas arqueológicos y también de los contemporáneos que existen en Colombia." Véase: FRIEDEMANN, Nina de y AROCHA, Jaime. $2^{\mathrm{a}}$ edición. Herederos del jaguar y la anaconda. Bogotá: Carlos Valencia Editores, 1985. P. 48.

${ }^{46}$ Como ha sido estudiado ya por GAMBOA HINESTROZA, Pablo. La escultura en la sociedad agustiniana. Bogotá: Departamento de Historia, Universidad Nacional de Colombia, 1981 (Trabajo Docente). 312 p. También: BUITRAGO GARCÍA, Eduardo. San Agustín una cultura precolombina enigmática. En: Archivo Historial. Vol III, No 66, oct de 1992. Pp. 13.-25.

${ }^{47}$ Sobre este tópico, léase: TORRES CARVAJAL, William. Uturuncu Runa : Historias de la gente jaguar. Bogotá: Zahir, 2004. 66 p.

${ }^{48}$ De nuevo la relación chamán - jaguar es representada en tiempos precolombinos en la cerámica: "The pieces in question depict four-ribbed San Pedro cacti in association with felines and volutes." En: SKILLMAN, Donald. Huachumero. Ethnic Tecnology Notes $N^{o}$ 22. San Diego: San Diego Museum of Man, 1990. P. 6.
} 
los productos chamánicos. ${ }^{49}$ Así, el conocimiento de la naturaleza obtenido por el chamán le permite a éste una ventaja crítica para la supervivencia de su sociedad, en medios supuestamente tan hostiles para el ser humano que no ha morado históricamente en estas territorialidades. Allí nace también una ética en la relación hombre naturaleza, pues existen relatos destinados a prevenir las nuevas generaciones contra los excesos de caza. En consecuencia los relatos sobre los "dueños de los animales" o sobre los animales protectores, ${ }^{50}$ cumplen así una función simbólica importante para estos pueblos. ${ }^{51}$

Por su parte, varios mitos de creación tienen en el jaguar uno de los personajes objeto del relato. Como el caso de Tama, el Niño Trueno, que es hijo de una mujer Páez dejada en cinta por un hombre Pijao convertido en jaguar. ${ }^{52}$ El pueblo Yaiguaje, del río Caquetá, es "gente jaguar", y Yavinape, un apellido entre los Curripaco de Guainía, refiere al nieto del tigre. Por lo anterior puede sugerirse que los indígenas americanos tuvieron un conocimiento profundo de la especie, ${ }^{53}$ que se arraigó así a su historia oral como un símbolo apropiado a sus necesidades nemotécnicas y de narración. El ocelotl, símbolo de uno de los meses del calendario Maya, sigue presente así durante el siglo XX en la oralidad indígena y relacionado principalmente con las cosmogonías y chamanes de estos pueblos.

Del otro lado encontramos el imaginario no indígena sobre la selva amazónica. Desde fines del siglo XIX las ideas occidentales van transformándose lentamente desde una visión de una naturaleza indomable y cruel frente al hombre, de infierno verde $;{ }^{54}$ pasando luego por la de naturaleza inagotable, de recursos abundantes sempiternos; ${ }^{55}$ hasta la de un espacio de trascendencia vital para la

\footnotetext{
${ }^{49}$ REICHEL-DOLMATOFF, Gerardo. El chamán y el jaguar: estudio de las drogas narcóticas entre los indios de Colombia. Tr. Félix Blanco. México: Siglo Veintiuno, 1978. 266 p.

${ }^{50}$ Durante las entrevistas en la cuenca hubo bastantes referencias a estos "dueños" que cuidan de la naturaleza, y especialmente de los sitios sagrados. Por su parte Ricardo FERREIRA describe como la Onça Cabocla (mujer-jaguar) acompaña y protege a los Xakriabá ante los invasores de su territorio. Véase: FERREIRA RIBEIRO, Ricardo. Sertão, lugar desertado : O cerrado na cultura de Minas Gerais. Vol. II. Belo Horizonte: Autêntica, 2006. P. 142.

${ }^{51}$ Muy seguramente a la manera como podían hacerlo los antiguos mexicanos en su relación con los objetos y el espacio. Cf. IBARRA GARCÍA, Laura. La visión del mundo de los antiguos mexicanos : Origen de sus conceptos de causalidad, tiempo y espacio. Guadalajara: Universidad de Guadalajara, 1995. $268 \mathrm{p}$.

${ }^{52}$ FRIEDEMANN, Nina de y AROCHA, Jaime. Op Cit. P. 58.

${ }^{53}$ Ocelote, palabra españolizada desde el nahua ocelotl, es un legado de la historia oral precolombina de este pueblo mesoamericano.

${ }^{54}$ Estas ideas serían condensadas magistralmente en La Vorágine, novela colombiana editada a mediados de los años 1920s. Véase: RIVERA, José Eustasio. La Vorágine. Bogotá: Panamericana, 2001. 236 p.

${ }^{55}$ Esa naturaleza que ha animado a los buscadores de tierras, maderas, petróleos y otros recursos naturales, especialmente desde mediados del siglo XX.
} 
humanidad por sus servicios ecosistémicos. ${ }^{56}$

Para que tal recorrido fuera concretándose a lo largo del siglo XX, se necesitó un proceso diacrónico en el cual se evidenciaba el desconocimiento profundo de la región por parte de los agentes colonizadores, mientras el movimiento ambiental iba adquiriendo la fuerza necesaria para advertir sobre los potenciales daños planetarios por la destrucción de la selva húmeda tropical.

Sin embargo, la percepción de la naturaleza inagotable históricamente no ha desaparecido o menguado como sí la de infierno verde. Por el contrario, esa fuente perpetua de recursos naturales, es aún la visión que sustenta la depredación de la flora y la fauna amazónicas y de que el ser humano no puede afectar su capacidad de resiliencia. Es también la que considera que eliminar al animal es la única vía de solucionar el conflicto generado con la fauna y su hábitat, ante la mirada indiferente de las autoridades ambientales.

Dos culturas tan diferentes (la indígena y la no indígena, para simplificarlo aquí) y una misma especie, detallan una relación diferente entre estas sociedades y la naturaleza en el tiempo. O sea que la primera en llegar logró adaptarse a través del tiempo e hizo suyo el endemismo biológico regional para la organización de sus sociedades autóctonas. Por el contrario, el prejuicio, la opulencia y el mercantilismo hicieron de las suyas en la relación de estas sociedades nativas con las forasteras. El encuentro de estas dos tendencias culturales definió de este modo el camino para que ese "infierno verde" pudiera convertirse en "tierra prometida", durante los orígenes de su colonización y en los tiempos de las cacerías masivas.

\section{CONCLUSIONES}

Los antecedentes sociales, económicos, culturales y ambientales aportados por la época cauchera a las subsiguientes cacerías de pieles de animales, ofrecen elementos de juicio para suponer que es particularmente hacia mediados de los años 1940s cuando comienza la cacería y comercialización masiva de pieles de felinos en la región estudiada. Estas pieles fueron destinadas principalmente a los mercados europeos, estadounidenses y japoneses.

Para una efectiva conservación de la especie jaguar es impostergable el estudio de la especie y la creación de unidades integrales de conservación, que se

\footnotetext{
${ }^{56}$ Entre otros, véase: MEGGERS, Betty J. Amazonia : hombre y cultura en un paraíso ilusorio. $2^{a}$ ed. Bogotá: Siglo XXI, 1981. 250 p., GHEERBRANT, Alain. El Amazonas, un gigante herido. Madrid: Aguilar, 1989. 192 p., D’ACHILLE, Bárbara. Uturunkusuyo : El territorio del jaguar: Perú: Parques nacionales y otras áreas de conservación ecológica. Lima: Banco Latino, 1996. 366 p., SISTEMA DE INFORMACIÓN AMBIENTAL DE COLOMBIA -SIAC-. Perfil del Estado de los Recursos Naturales y del Medio Ambiente en Colombia 2001. Bogotá: Instituto de Hidrología, Meteorología y Estudios Ambientales, 2002. 598 p.
} 
compadezcan con las necesidades de protección de hábitat que requiere el mayor felino del continente americano.

Existe la necesidad urgente de crear programas ambientales concretos para la conservación del jaguar en áreas donde históricamente ha pasado a convertirse en un problema por su ataque a los animales domesticados o a los hatos ganaderos de la región.

El hecho de que existan mejores posibilidades de conservación de la especie en zonas fronterizas de Brasil, Perú y Colombia, implica consecuentemente la cooperación internacional como garantía para la consecución de resultados relevantes, frente a la pérdida acelerada de la biodiversidad en la cuenca alta y sus consecuencias para el área en general.

No sólo las cacerías han generado históricamente una presión excesiva sobre el jaguar en las cuencas señaladas. De la misma forma pueden considerarse el crecimiento demográfico, la deforestación, las obras de infraestructura, la industria petrolera, la ganadería y los cultivos ilícitos, que se han desarrollado principalmente en la zona del piedemonte y de las selvas altas.

Para la ejecución de este proyecto de investigación fueron necesarios los esfuerzos de muchas personas. En primer lugar, agradezco al proyecto Historia Ambiental de Colombia y América Latina, HACAL, que ha consolidado la investigación de esta disciplina en la Universidad Nacional de Colombia. También a la Facultad de Ciencias Humanas por su apoyo para llegar hasta los lugares objeto del trabajo de campo. Finalmente, a todas las personas quienes con sus informaciones, entrevistas o diálogos aportaron para aclarar la trama y llevar a feliz término esta historia.

\section{BIBLIOGRAFÍA}

ARAGÓN VACA, Luis E. (Editor). Populações da Pan-Amazônia. Belém: Núcleo de Altos Estudos Amazônicos, 2005. 204 p.

ARANGO OCHOA, Raúl y SÁNCHEZ GUTIÉRREZ, Enrique. Los pueblos indígenas de Colombia en el umbral del nuevo milenio. Bogotá: Departamento Nacional de Planeación, 2004. 526 p.

ARANA, Julio César. Arana explica la Casa Arana: Extractos de la declaración ante el parlamento británico. En: Credencial Historia, No 160, 2003.

BAPTISTE BALLERA, Luis Guillermo et al. Tras las huellas del jaguar. Inédito. Bogotá: Corporación Grupo Ecológico GEA, 1993. 180 p. 
BARHAM, Bradford L. y COOMES, Oliver T. Reinterpreting the Amazon Rubber Boom: Investment, the State, and Dutch Disease. En: Latin American Research Review, Vol. 29, No 2, 1994, P. 89. pp. 73-109

BEAUGRANDE, Robert de. Curso Internacional: Análisis del Discurso en las Ciencias Sociales, la Cultura y el Territorio. Bogotá: UNIVERSIDAD NACIONAL DE COLOMBIA - INSTITUTO CARO Y CUERVO, 2002. 232 p.

BUITRAGO GARCÍA, Eduardo. San Agustín una cultura precolombina enigmática. En: Archivo Historial. Vol III, No 66, oct de 1992. Pp. 13.-25.

CABELLOS CARRO, Paz. Iconografía y significado del jaguar en pueblos mesoamericanos chorotecas y nicaraos. En: Revista Española de Antropología, Madrid, N 10, 180, pp. 43-66.

CARDOSO DA SILVA, José Maria. Áreas de endemismo da Amazônia: passado e futuro. En: Ciência \& Ambiente. $\mathrm{N}^{\mathrm{o}} 31$, jul-dic de 2005.

CARRIZOSA UMAÑA, Julio. Cambios en la amazonia Colombiana en los últimos $\mathbf{3 0 0}$ años. En: Revista de la Academia Colombiana de Ciencias Exactas, Físicas y Naturales. Vol. 27, No 64, febrero de 1989. pp. 119-123.

CASTRO CAYCEDO, Germán. Mi alma se la dejo al diablo. Bogotá: Plaza y Janés, 1982. 344 p.

CASTRO HERRERA, Guillermo. La crisis ambiental y las tareas de la Historia en América Latina. En: Papeles de población. No 24, Abril-junio de 2000. Pp. 37-60.

COSTA AZEVEDO, José de. Carta Hydrographica do rio Japurá. Rio de Janeiro: Imperial Instituto Artístico, 1871. 34 p.

Carta do Rio Içá: Levantada em 1868 sob a direcção do Commissario. Rio de Janeiro: Lithographia do Archivo Militar, 186820 p.

COVARRUBIAS, Miguel. El águila, el jaguar y la serpiente: Arte indígena americano : América del Norte: Alaska, Canadá, los Estados Unidos. Trad. Sol Arguedas. México: Universidad Nacional Autónoma de México, 1961. 340 p.

D'ACHILLE, Bárbara. Uturunkusuyo: El territorio del jaguar: Perú : Parques nacionales y otras áreas de conservación ecológica. Lima: Banco Latino, 1996. 366 p.

DAVIS, Whitney. So-Called Jaguar-Human Copulation Scenes in Olmec Art. En: American Antiquity, Vol. 43, No 3 (Jul., 1978), pp. 453-457. 
DAGGETT, Pierre M. y HENNING, Dale R. The Jaguar in North America. En: American Antiquity, Vol. 39, No 3 (Jul., 1974), pp. 465-469

DOMínguEZ, Camilo. ¿Se urbaniza la Amazonia?: El anillo de poblamiento amazónico. En: Iniciativa Amazónica, Revista Trimestral de los Países de la Amazonia, nº 1, ago 2001. y GÓMEZ, Augusto. Nación y etnias: Conflictos territoriales en la Amazonia colombiana 1750-1933. Santafé de Bogotá: COAMA, Unión Europea, 1994. 246 p.

FERREIRA RIBEIRO, Ricardo. Sertão, lugar desertado: O cerrado na cultura de Minas Gerais. Vol. II. Belo Horizonte: Autêntica, 2006. 376 p.

FLÓREZ MALAGÓN, Alberto Guillermo. El campo de la historia ambiental y las perspectivas para su desarrollo en Colombia. Bogotá: Departamento de Historia - Instituto de Estudios Ambientales, Universidad Javeriana, 1998. 122 p.

FRIEDEMANN, Nina de y AROCHA, Jaime. $2^{\text {a }}$ edición. Herederos del jaguar y la anaconda. Bogotá: Carlos Valencia Editores, 1985. 384 p.

GAMBOA HINESTROZA, Pablo. La escultura en la sociedad agustiniana. Bogotá: Departamento de Historia, Universidad Nacional de Colombia, 1981 (Trabajo Docente). 312 p.

GHEERBRANT, Alain. El Amazonas, un gigante herido. Madrid: Aguilar, 1989. 192 p.

GÓMEZ, Augusto et al. Caucherías y conflicto colombo-peruano : testimonios 1904-1934. Santafé de Bogotá: Disloque Editores, 1995. 318 p.

HOOGESTEIJN, Rafael. Manual sobre problemas de depredación causados por jaguares y pumas en hatos ganaderos. Apure: Wildlife Conservation Society, s.d. 39 p.

IBARRA GARCÍA, Laura. La visión del mundo de los antiguos mexicanos : Origen de sus conceptos de causalidad, tiempo y espacio. Guadalajara: Universidad de Guadalajara, 1995. 268 p.

INSTITUTO DE INVESTIGACIÓN DE RECURSOS BIOLÓGICOS ALEXANDER VON HUMBOLDT (IAvH). Los felinos como especies focales y de alto valor cultural. (Especies Colombianas, $\mathrm{n}^{\circ} 7$ ).

LEAL, Claudia. La naturaleza en los estudios sociales. Pp. 123-137. En: PALACIO CASTAÑEDA, Germán y ULLOA, Astrid (eds.). Repensando la naturaleza. 
Encuentros y desencuentros disciplinarios en torno a lo ambiental. Bogotá: Universidad Nacional de Colombia, Instituto Colombiano de Antropología e Historia y Colciencias, 2002. 246 p.

LEONARDI, Victor Paes de Barros. Os historiadores e os rios: Natureza e ruína na Amazônia Brasileira. Brasília: Paralelo 15, Universidade de Brasilia, 1999. $272 \mathrm{p}$.

MÁRQUEZ, Germán. Mapas de un fracaso. Naturaleza y conflicto en Colombia. Bogotá: Universidad Nacional de Colombia, 2004. 102 p.

MARTÍNEZ ALIER, Juan. Ecologia dos Pobres e Conflitos Distributivos Ecológicos. Instituto de Estudos Avançados, Universidade de São Paulo. Junio 4 de 2007.

MCNEILL, J. R. The Nature of Environmental History. En: History and Theory, No 42 (Dic., 2003), pp. 5-43.

Something New Under The Sun: An Environmental History of the Twentieth-Century World. New York: Norton \& Company, 2000. 422 p. MEDELLÍN, Rodrigo A. et al. El jaguar en el nuevo milenio. México: Fondo de Cultura Económica, 2002. 648 p.

MEGGERS, Betty J. Amazonia : hombre y cultura en un paraíso ilusorio. 2a ed. Bogotá: Siglo XXI, 1981. 250 p.

MORA CAMARGO, Santiago. Amazonía: pasado y presente de un territorio remoto : el ámbito, la historia y la cultura vista por antropólogos y arqueólogos. Bogotá: Universidad de los Andes y CESO, 2006. 268 p.

MOSLEY, Stephen. Common Ground: Integrating Social and Environmental History. En: Journal of Social History. Pp. 915-933.

PALACIO CASTAÑEDA, Germán y ULLOA, Astrid (eds.). Repensando la naturaleza. Encuentros y desencuentros disciplinarios en torno a lo ambiental. Bogotá: Universidad Nacional de Colombia, Instituto Colombiano de Antropología e Historia y Conciencias, 2002. 246 p.

PAYÁN, Esteban y TRUJILLO Luis A. The Tigrilladas in Colombia. En: CAT NEWS. No 44, 2006. P. 25-28.

PEREIRA da CUNHA, H. Viagems y caçadas em Mato Gosso: Trez semanas 
em companhia de Th. Roosevelt. Rio de Janeiro: Francisco Alves, 1919. 232 p. PINEDA CAMACHO, Roberto. Holocausto en el Amazonas: historia social de la Casa Arana. Bogotá: Planeta, 2000. 255 p.

PITMAN, Nigel et al (eds). Perú: Ampiyacu, Apayacu, Yaguas, Medio Putumayo. Rapid Biological Inventories Report 12. Chicago: The Field Museum, 2004. 274 p.

PROGRAMA DE LAS NACIONES UNIDAS PARA EL MEDIO AMBIENTE. Perspectivas del Medio Ambiente Mundial. GEO4: medio ambiente para el desarrollo. Dinamarca: PNUMA, 2007. 544 p.

REICHEL-DOLMATOFF, Gerardo. El chamán y el jaguar: estudio de las drogas narcóticas entre los indios de Colombia. Tr. Félix Blanco. México: Siglo Veintiuno, 1978. 266 p.

ROMERO RAFFO, Manuel. Canaguaro, la guerra de los tigreros. Bogotá: Parature Editores, 2005. 180 p.

RIOS ZAÑARTU, Mario César. Historia de la Amazonia Peruana (compendio). $2^{\text {a }}$ Ed. Iquitos: CETA, 1999. 244 p.

RUEDA, Martha Emilia. La biodiversidad. Un asunto nacional con implicaciones globales. En: Pensamiento Jurídico. No 2, 1995, Bogotá. P. 65-74.

SAUER, Carl O. Hacia una geografía histórica: Discurso a la Asociación Norteamericana de Geógrafos. Trad. Guillermo Castro H. Louisiana, 1940.

SERRANO MOYA, Edgar David. El modelo ganadero de la gran hacienda : Un paso atrás en el desarrollo del Caquetá. Trabajo de Investigación. Florencia: Universidad de la Amazonía, 1994. 164 p.

SEYMOUR, Kevin L. Panthera onca. En: Mammalian Species. No 340, octubre de 1989. p. 1-9.

SISTEMA DE INFORMACIÓN AMBIENTAL DE COLOMBIA -SIAC-. Perfil del Estado de los Recursos Naturales y del Medio Ambiente en Colombia 2001. Bogotá: Instituto de Hidrología, Meteorología y Estudios Ambientales, 2002. 598 p.

SKILLMAN, Donald. Huachumero. Ethnic Tecnology Notes $\mathbf{N}^{\circ}$ 22. San Diego: San Diego Museum of Man, 1990. 32 p.

TORRES CARVAJAL, William. Uturuncu Runa: Historias de la gente jaguar. Bogotá: Zahir, 2004. 66 p.

TRIANA ANTORVEZA, Adolfo. La Amazonia: economía y derecho 
internacional. En: Pensamiento Jurídico. No 6, 1996. Bogotá. Pp. 123-153.

URIBE BOTERO, Eduardo. The Evolution of Colombian Environmental Institutions: 1971-2004. Bogotá: Universidad de los Andes, 2005. 92 p.

UNIVERSIDAD NACIONAL DE COLOMBIA - INSTITUTO CARO Y CUERVO. Curso Internacional: Análisis del Discurso en las Ciencias Sociales, la Cultura y el Territorio. Bogotá: UNAL, 2002. 232 p.

WEBER, William y RABINOWITZ, Alan. A global Perspective on Large Carnivore Conservation. En: Conservation Biology, Vol. 10, No 4 (Aug., 1996), pp. 1046-1054.

WORSTER, Donald. Transformaciones de la tierra. Una antología mínima de Donald Worster. Trad. Guillermo Castro Herrera. Panamá: s. e., 2000. 108 p. WUST, Walter H. Los gatos salvajes del Perú. En: Peru : El Dorado. № 15 (Abr-jun de 1997), pp 4-12.

ZULOAGA VILLAMIZAR, Juan Gerardo. Densidad de población, hábitos alimenticios y anotaciones sobre hábitat natural del jaguar (Panthera onca L.) en la depresión inundable del Bajo San Jorge, Colombia. Trabajo de grado. Bogotá: Departamento de Biología, Universidad Nacional de Colombia, 1995. $120 \mathrm{p}$. 